\title{
THE RATE OF URINARY TRACT INFECTIONS FOLLOWING TRANSRECTAL ULTRASOUND-GUIDED BIOPSY OF PROSTATE IN BABOL, NORTHERN IRAN
}

\author{
Bahram Shekarchi', Masomeh Bayani², Soraya Khafri3 , Hamid Shafi ${ }^{4}$
}

1MD, Student Research Committee, School of Medicine, Babol University of Medical Sciences, Babol, Iran.

${ }^{2}$ Associate Professor, Infectious Diseases and Tropical Medicine Research Center, Health Research Institute, Babol University of Medical Sciences, Babol, Iran.

${ }^{3}$ Assistant Professor, Department of Biostatistics and Epidemiology, Medicine Faculty, Babol University of Medical Sciences, Babol, Iran. ${ }^{4}$ Professor, Infertility and Reproductive Health Research Center, Health Research Institute, Babol University of Medical Sciences, Babol, Iran.

\section{BACKGROUND}

\section{ABSTRACT}

Symptomatic urinary tract infections following transrectal prostate biopsy are among the most dangerous and important complications of this procedure. Considering the importance of infectious and non-infectious complications after transrectal prostate biopsy, this study was conducted to determine the rate of symptomatic urinary tract infection following transrectal ultrasound-guided biopsy of prostate in Babol, north of Iran.

\section{MATERIALS AND METHODS}

This cross-sectional study was conducted in the Shahid Beheshti and Babol Clinic teaching hospitals. All patients with either increased concentrations of prostate-specific antigen (PSA) (>4.0 ng/mL) or abnormal digital rectal examination, who underwent TRUS biopsy during 2010-2017, were included in this research. A case was defined as a patient who received prophylactic antibiotics but presented with UTI symptoms, such as frequency, dysuria, etc. Chi-square test was used to evaluate the association between urinary tract infection and variables of age, PSA level and pathology results. The significance level of all tests was considered 0.05

\section{RESULTS}

Out of 2104 patients enrolled, 141 patients (6.7\%) suffered from symptomatic urinary tract infections. The mean age of patients was $68.85 \pm 9.59$ years. A significant relation was observed between pathology results and the infection $(\mathrm{p}<0.001)$, but there was no association between the infection and factors of age and PSA level. After admission, the infected patients received different antibiotics.

\section{CONCLUSION}

The prevalence of urinary tract infections following transrectal biopsy of the prostate was high in Babol. Therefore, measures need to be taken to control this complication by health professionals.

\section{KEY WORDS}

Urinary Tract Infections, Prostate, Biopsy, Ultrasonography.

HOW TO CITE THIS ARTICLE: Shekarchi B, Bayani M, Khafri S, et al. The rate of urinary tract infections following transrectal ultrasound-guided biopsy of prostate in Babol, Northern Iran. J. Evolution Med. Dent. Sci. 2018;7(50):5390-5393, DOI: $10.14260 /$ jemds/2018/1192

\section{BACKGROUND}

Prostate cancer is the most common tumor diagnosed among older men and is the sixth cause of cancer-related deaths in men.(1) Prostate-specific antigen (PSA) test and digital rectal examination are usual methods for diagnosis of prostate cancer. However, diagnosis is only through transurethral resection of the prostate (TURP) or open prostatectomy. Prostate biopsy methods include perineal, transrectal and magnetic resonance imaging (MRI) fusion biopsy.

'Financial or Other Competing Interest': The Authors would like to thank the Vice Chancellor for the Research of Babol University of Medical Sciences for Financial Support.

Submission 02-11-2018, Peer Review 26-11-2018

Acceptance 03-12-2018, Published 10-12-2018.

Corresponding Author:

Dr. Hamid Shafi,

Department of Urology, School of Medicine,

Babol University of Medical Sciences,

Ganjafrooz Street, Babol,

Mazandaran, Iran.

E-mail: dr_hamidshafi@yahoo.com

DOI: $10.14260 /$ jemds/2018/1192
Transrectal ultrasound-guided (TRUS) biopsy is substituted to primary perineal prostate biopsy methods. MRI fusion biopsy is a newer method compared with the other two methods that benefits from MRI and TRUS both and can detect the possible cancer regions better, but it has not became a routine procedure due to being expensive. ${ }^{(2)}$ Indications for prostate biopsy is increased PSA and abnormal digital rectal examination.(3) In our country, Iran, although we do not have a precise statistics but considering the PSA test, the number of prostate biopsy has significantly increased.

The complications related to prostate biopsy can vary from self-limited to severe and life threatening. The most common complications following prostate biopsy include infection, bleeding, and urinary retention.(4-7) The complications related to infection include asymptomatic bacteriuria, urinary system infection and sepsis.(8) One of the biggest worries of recent reports is increase in admitted men to hospital due to considerable infection following prostate biopsy. ${ }^{(9)}$ Although several reasons can explain this increased rate, but it seems bacterial resistance and lack of efficient 
therapeutic regimen are the most important etiologic factors.(10-15) Considering that the most frequent method of prostate biopsy is through rectum, concerns are mainly about entering rectal bacteria into urinary tract. The studies showed that transient asymptomatic bacteriuria occur in nearly $5 \%$ of people underwent biopsy and did not use appropriate antibiotic prophylaxis.(8) Less than $2-3 \%$ of men will have progressive symptomatic urinary tract infection (UTI) (e.g., dysuria, frequency, urgency, etc.), which can be improved with efficient oral antibiotic.(8) Prophylaxis in the patients undergoing TRUS biopsy is ofloxacin and metronidazole tablets from 3 days before the procedure and ten days after the procedure, plus amikacin injection during the procedure. Despite this prophylaxis regimen, some patients are referred with compliant of fever, chills and UTI.(16,17)

Considering the importance of symptomatic UTI and its life-threatening outcomes, and also the costs imposed on the patients and community because of complications, we aimed to do an eight-year study on the patients underwent prostate biopsy in Babol, so that we can take a step toward prevention, selection of appropriate therapy and finally improvement of local and national health.

\section{MATERIALS AND METHODS}

Locations- This cross-sectional study was conducted during 2010-2017 in the Shahid Beheshti teaching hospital, (affiliated to Babol University of Medical Sciences, Babol, Northern Iran) and Babol Clinic Hospital.

Inclusion and Exclusion Criteria- The inclusion criteria were as follows: All patients with either increased concentrations of PSA $(>4.0 \mathrm{ng} / \mathrm{mL})$ or abnormal digital rectal examination, who underwent TRUS biopsy. Among them, we only included those patients who were agreed to participate to this research. Patients whose biopsy pathology results were not available, were excluded from further investigation.

Biopsy Procedure- All biopsies were done by the senior urologist using a standard ultrasound. The patients received prophylactic antibiotics prior to their procedure. The local anaesthesia was induced by lidocaine gel. Duration of the biopsy procedure lasted maximum 15 minutes.

Data Collection- After obtaining informed consent from the patients, the necessary data were collected by a checklist, including demographic information (Sex, age, education, residence, and occupation), clinical symptoms and signs, pathology results (Normal, prostatitis, benign prostate hyperplasia $[\mathrm{BPH}]$, prostate cancer) and admission information (Time of refer after biopsy, antibiotics, hospitalization duration and laboratory results). A case was defined as a patient who received prophylactic antibiotics but presented with UTI symptoms, such as frequency, dysuria, etc.

Statistical Analysis- For data analysis, SPSS statistical software was used. The data underwent the descriptive analysis test to provide the number, percentage, and mean \pm standard deviation (SD). Furthermore, chi-square test was used to evaluate the association between UTI and variables of age, PSA level and pathology results. A pvalue $<0.05$ was considered statistically significant.

Ethical Issues- The present research was approved by the ethical committee of Babol University of Medical Sciences with code of MUBABOL.REC.1395.46. After explanation of the aim of study for the subjects, we collected the informed consent from them. The patients' information was kept confidential.

\section{RESULTS}

In total, 2104 patients were included in this study. Their pathology findings were collected form the pathology center. Out of 2104 subjects, 141 (6.7\%) had symptomatic UTI. Patients' characteristics were summarized in Table 1 . The mean age of patients was $68.85 \pm 9.59$ years old. The information of biopsy was not available for 33 patients, however for others, symptoms were started in the first 12 hours of biopsy in 3 patients, in 12-24 hours of biopsy in 48 patients, in 48-72 hours of biopsy in 2 patients and in 72 hours or later of biopsy in 10 patients.

After admission, the infected patients received different medications. Twenty-seven patients (19.1\%) were cured by meropenem, 4 patients $(2.8 \%)$ by fluoroquinolones (ciprofloxacin/ofloxacin), and 1 patient $(0.7 \%)$ by aminoglycoside. Others were treated by combination antibiotic therapy, that is, 2 patients (1.4\%) with fluoroquinolone plus cephalosporin, 21 patients (14.9\%) with fluoroquinolone plus aminoglycoside, 2 patients $(1.4 \%)$ with metronidazole plus cephalosporin, 43 patients $(30.5 \%)$ with cephalosporin and aminoglycoside, 8 patients $(5.7 \%)$ with meropenem, fluoroquinolone and metronidazole, 2 patients $(1.4 \%)$ with meropenem, fluoroquinolone and aminoglycoside, and finally 2 patients (1.4\%) with meropenem, cephalosporin and aminoglycoside.

Table 2 shows the relationship between UTI and some variables. As indicated, a significant relation was observed between pathology results and infection according to chisquare test $(\mathrm{p}<0.001)$. On the other hand, no any significant associations were seen between infection and variables of age and PSA level.

\begin{tabular}{|c|c|c|}
\hline Variables & Frequency & Percent \\
\hline \multicolumn{2}{|c|}{ Education } \\
\hline Illiterate & 45 & 40.5 \\
\hline Lower Diploma & 34 & 30.6 \\
\hline Diploma & 18 & 16.2 \\
\hline Higher Diploma & 14 & 12.6 \\
\hline \multicolumn{2}{|c|}{ Residence } \\
\hline Urban Occupation \\
\hline Rural & 34 & 25.8 \\
\hline Self-Employed & 90 & 74.2 \\
\hline Employee & 2 & 1.8 \\
\hline Retired & 2 & 16.1 \\
\hline Unemployed & 3 & 1.8 \\
\hline Times of Onset of Symptoms (Hour) \\
\hline$<12$ & 45 & 41.7 \\
\hline $12-24$ & 48 & 44.4 \\
\hline $24-48$ & 2 & 1.9 \\
\hline $48-72$ & 10 & 9.3 \\
\hline$>72$ & \\
\hline Table 1. Characteristics of Included Patients \\
\hline
\end{tabular}




\begin{tabular}{|c|c|c|c|}
\hline Variables & \begin{tabular}{|c|} 
Patients \\
Infected with \\
UTI* (n, \%)
\end{tabular} & $\begin{array}{c}\text { Patients not } \\
\text { Infected with } \\
\text { UTI (n, \%) }\end{array}$ & p-Value \\
\hline \multicolumn{3}{|c|}{ Age } & \multirow{3}{*}{0.084} \\
\hline$\leq 64$ & $40(5.4)$ & $698(94.6)$ & \\
\hline$>65$ & $101(7.4 \%)$ & $1265(92.6)$ & \\
\hline \multicolumn{3}{|c|}{ PSA** Level } & \multirow{4}{*}{0.164} \\
\hline$<4$ & $2(4.1)$ & $47(95.9)$ & \\
\hline $4-10$ & $52(7.8)$ & $612(92.2)$ & \\
\hline$>10$ & $76(10.1)$ & $679(89.9)$ & \\
\hline \multicolumn{3}{|c|}{ Pathology Results } & \multirow{7}{*}{$<0.001$} \\
\hline Normal & $3(1.1)$ & $276(98.9)$ & \\
\hline $\mathrm{BPH}^{* * *}$ & $57(12.3)$ & $407(87.7)$ & \\
\hline Prostate Cancer & $39(6.3)$ & $578(93.7)$ & \\
\hline Prostatitis & $21(4.8)$ & $420(95.2)$ & \\
\hline $\begin{array}{c}\text { BPH \& Prostate } \\
\text { Cancer }\end{array}$ & $0(0)$ & $6(100)$ & \\
\hline BPH \& prostatitis & $21(7.1)$ & $276(92.9)$ & \\
\hline
\end{tabular}

* Urinary tract infection, ** Prostate-specific antigen, *** Benign prostate hyperplasia

\section{DISCUSSION}

This study was conducted with the aim of evaluating the rate of UTI following prostate biopsy in Babol. As found, 141 of $2104(6.7 \%)$ patients who underwent biopsy had UTI. Shigehara et al.(18) in their study in 2008 on 457 patients stated that 6 patients (1.3\%) experienced infection. in their study, Choi et al.(19) Reported that 39 of 1195 (3.1\%) Korean patients were infected after biopsy. Also, Marino et al.(20) did a three-year study in the United States and declared that 25 of 455 (5.49\%) patients reported UTI. Besides, Kandemir et al.(21) In Turkey in 2016 stated a rate of $6.91 \%$ for UTI among 2215 patients underwent TRUS biopsy. These differences can be related to type of bacterium led to infection, antibiotic choice and resistance of the microorganisms to antibiotics. Kandemir et al.(21) Stated that fluoroquinolone-resistance Escherichia coli bacteria, which were responsible for the infection, have significantly increased after 2008 (95.9\%) compared with before 2008 (73.5\%).

Our results revealed that rate of UTI following TRUS biopsy significantly differ between different pathology results and this rate was significantly more in patients with $\mathrm{BPH}$ $(12.3 \%)$ than in other patients. This finding was in consistent with some studies, but in contrast to some others.(22-24).

Different studies assessed various factors related to the patients and the TURS biopsy procedure that may predict which groups of men are more at risk of UTI.(3,22,24) The known risk factors included underlying comorbidities, especially diabetic mellitus and recent admission.(3,22) Carignan et al.(22) Demonstrated that patients admitted during the previous month of biopsy were infected to urosepsis more than those who were not admitted. Other potential risk factors were also reported. Simsir et al.(25) Showed that the patients who used the urethra catheter for a long time were more at risk of infection after prostate biopsy compared with those who did not use it.

The results of our study showed that $3.3 \%$ of the patients had normal PSA level. Considering that one of the indications for prostate biopsy is abnormal PSA level, our results are reasonable. It has been shown that screening for prostate cancer by PSA level can decrease incidence of metastatic cancers and its mortality by $41 \%$ and $20 \%$, respectively. ${ }^{(26)}$ Additionally, a population-based screening study in Gutenberg indicated that PSA screening led to increase in cancer prostate by $44 \%$ after 14 years of follow-up.(27) In opposite of these advantages, screening has also some disadvantages, such as over diagnosis, consequently, false positive results cause unnecessary prostate biopsies which are associated with complications.(24) Therefore, we need to pay attention to the patients' symptoms as well and consider the fact that PSA level can increase in different conditions, such as trauma, prostatitis and rectal examination of prostate, and the patients should not undergo prostate biopsy with only high PSA. Ehdaie et al.(28) Also emphasized that increased PSA following prostatitis can increase complications due to prostate biopsy.

In this investigation, we witnessed that despite the higher rate of infection in patients aged more than 65 years old than in those aged $<65$ years old, this difference was not significant. This finding was in agreement with other reports. $(3,29)$

A limitation of our study was that we could not access some patients' information due to lack of the records or their destruction. We propose to perform a new study with greater sample size at national scale to assess the short- and longterm clinical outcomes of TRUS biopsy. We also suggest addressing the rate of antibiotic resistance in patients undergoing the biopsy.

\section{CONCLUSION}

According to our results, the rate of UTI after prostate biopsy was high in our region. Also, a significant positive relation was observed between BPH and UTI following biopsy. Therefore, it seems that evaluation of the patients suffering from BPH in terms of bacteriuria and their treatment can help in reduction of such infection rates. Moreover, considering that we did not see any association between age and UTI, it appears that concerns about complication due to prostate biopsy is unnecessary in the elderly and such group can benefit from biopsy like others.

\section{ACKNOWLEDGMENTS}

The authors would like to thank the Vice Chancellor for the Research of Babol University of Medical Sciences for financial support. We are also thankful to Ms. Sekineh Kamali Ahangar, member of Clinical Research Development Center of Shahid Beheshti Hospital, for her help in preparing the manuscript.

\section{REFERENCES}

[1] Center MM, Jemal A, Lortet-Tieulent J, et al. International variation in prostate cancer incidence and mortality rates. Eur Urol 2012;61(6):1079-92.

[2] Terris M. Prostate ultrasonography. In: Walsh P, Partin, eds. Campbell's Urology. $8^{\text {th }}$ edn. Philadelphia: Saunders 2002: p. 3038.

[3] Loeb S, Carter HB, Berndt SI, et al. Complications after prostate biopsy: data from SEER-Medicare. J Urol 2011;186(5):1830-4. 
[4] Akduman B, Akduman D, Tokgöz H, et al. Long-term fluoroquinolone use before the prostate biopsy may increase the risk of sepsis caused by resistant microorganisms. Urology 2011;78(2):250-5.

[5] Berger AP, Gozzi C, Steiner H, et al. Complication rate of transrectal ultrasound guided prostate biopsy: a comparison among 3 protocols with 6,10 and 15 cores. J Urol 2004;171(4):1478-81.

[6] Jeon SS, Woo SH, Hyun JH, et al. Bisacodyl rectal preparation can decrease infectious complications of transrectal ultrasound-guided prostate biopsy. Urology 2003;62(3):461-6.

[7] Tal R, Livne PM, Lask DM, et al. Empirical management of urinary tract infections complicating transrectal ultrasound guided prostate biopsy. J Urol 2003;169(5):1762-5.

[8] Zani EL, Clark OA, Netto RN Jr. Antibiotic prophylaxis for transrectal prostate biopsy. Cochrane Database Syst Rev 2011;(5):CD006576.

[9] Batura D, Rao GG, Nielsen PB. Prevalence of antimicrobial resistance in intestinal flora of patients undergoing prostatic biopsy: implications for prophylaxis and treatment of infections after biopsy. BJU Int 2010;106(7):1017-20.

[10] Horcajada JP, Busto M, Grau S, et al. High prevalence of extended-spectrum beta-lactamase-producing enterobacteriaceae in bacteremia after transrectal ultrasound-guided prostate biopsy: a need for changing preventive protocol. Urology 2009;74(6):1195-9.

[11] Lange D, Zappavigna C, Hamidizadeh R, et al. Bacterial sepsis after prostate biopsy-a new perspective. Urology 2009;74(6):1200-5.

[12] Shandera KC, Thibault GP, Deshon GE Jr. Efficacy of one dose fluoroquinolone before prostate biopsy. Urology 1998;52(4):641-3.

[13] Shandera KC, Thibault GP, Deshon GE Jr. Variability in patient preparation for prostate biopsy among American urologists. Urology 1998;52(4):644-6.

[14] Steensels D, Slabbaert K, De Wever L, et al. Fluoroquinolone-resistant E. coli in intestinal flora of patients undergoing transrectal ultrasound-guided prostate biopsy-should we reassess our practices for antibiotic prophylaxis? Clin Microbiol Infect 2012;18(6):575-81.

[15] Taylor AK, Zembower TR, Nadler RB, et al. Targeted antimicrobial prophylaxis using rectal swab cultures in men undergoing transrectal ultrasound guided prostate biopsy is associated with reduced incidence of postoperative infectious complications and cost of care. J Urol 2012;187(4):1275-9.

[16] Bateni ZH, Shahrokh H, Salimi H, et al. Single-dose versus multiple-dose ciprofloxacin plus metronidazole prophylaxis in transrectal ultrasound-guided biopsy of the prostate: a randomized controlled trial. Acta Med Iran 2014;52(9):664-70.
[17] Batura D, Rao GG, Bo Nielsen P, et al. Adding amikacin to fluoroquinolone-based antimicrobial prophylaxis reduces prostate biopsy infection rates. BJU Int 2011;107(5):760-4.

[18] Shigehara K, Miyagi $T$, Nakashima $T$, et al. Acute bacterial prostatitis after transrectal prostate needle biopsy: clinical analysis. J Infect Chemother 2008;14(1):40-3.

[19] Choi JW, Kim TH, Chang IH, et al. Febrile urinary tract infection after prostate biopsy and quinolone resistance. Korean J Urol 2014;55(10):660-4.

[20] Marino K, Parlee A, Orlando R, et al. Comparative effectiveness of single versus combination antibiotic prophylaxis for infections after transrectal prostate biopsy. Antimicrob Agents Chemother 2015;59(12):7273-5.

[21] Kandemir Ö, Bozlu M, Efesoy 0, et al. The incidence and risk factors of resistant E. coli infections after prostate biopsy under fluoroquinolone prophylaxis: a single-centre experience with 2215 patients. J Chemother 2016;28(4):284-8.

[22] Carignan A, Roussy JF, Lapointe V, et al. Increasing risk of infectious complications after transrectal ultrasound-guided prostate biopsies: time to reassess antimicrobial prophylaxis? Eur Urol 2012;62(3):4539.

[23] Lindert KA, Kabalin JN, Terris MK. Bacteremia and bacteriuria after transrectal ultrasound guided prostate biopsy. J Urol 2000;164(1):76-80.

[24] Loeb S, van den Heuvel S, Zhu X, et al. Infectious complications and hospital admissions after prostate biopsy in a European randomized trial. Eur Urol 2012;61(6):1110-4.

[25] Simsir A, Kismali E, Mammadov R, et al. Is it possible to predict sepsis, the most serious complication in prostate biopsy? Urol Int 2010;84(4):395-9.

[26] Schröder FH, Hugosson J, Roobol MJ, et al. Screening and prostate-cancer mortality in a randomized European study. N Engl J Med 2009;360(13):1320-8.

[27] Hugosson J, Carlsson S, Aus G, et al. Mortality results from the Göteborg randomised population-based prostate-cancer screening trial. Lancet Oncol 2010;11(8):725-32.

[28] Ehdaie B, Vertosick E, Spaliviero M, et al. The impact of repeat biopsies on infectious complications in men with prostate cancer on active surveillance. J Urol 2014;191(3):660-4.

[29] Berger RE, Krieger JN, Rothman I, et al. Bacteria in the prostate tissue of men with idiopathic prostatic inflammation. J Urol 1997;157(3):863-5. 